\title{
Automated clinical chemistry
}

\section{By T. P. WhiteneAd, Queen Elizabeth Hospital, Edgbaston, Birmingham}

The workload of the clinical chemistry laboratory doubles every 4 or 5 years. This increase occurs in teaching and non-teaching hospital laboratories in this country and in many other countries abroad. Such increases have forced new approaches in laboratory techniques and laboratory organization. In the Department of Biochemistry at the Queen Elizabeth Hospital, Birmingham, work study of the systems identified three 'bottle-necks'. These were first, the transport 'bottle-neck', that is, getting specimens from the ward to the laboratory and the report back from the laboratory to the ward. Second, the analytical technique 'bottle-neck' and thirdly, the data-processing 'bottle-neck'. New transport systems can only be introduced with prohibitive capital outlay. The analytical technique 'bottle-neck' has been intensively studied and the AutoAnalyzer is in very common use in hospital laboratories.

During the last years, attention has been focused upon data processing and the introduction of on-line computer facilities in many laboratories has already taken place or is about to take place. The computer in the clinical chemistry laboratory performs tasks which can be conveniently divided into two: first, acquiring data from the analytical equipment, calculating the result and associating it with patient identification; second, data-processing results, particularly with regard to quality control and other management techniques. Experience with computer work has shown that it can save clerical work by scientific staff but, what is more important, it is capable of providing information which was previously hidden, e.g., on-line monitoring of the AutoAnalyzer has shown that much more information can be obtained from the analogue signal normally transferred to a chart recorder. Blockages can be detected earlier and other defects in the system can be identified more precisely. In addition, data processing of results can lead to a much greater appreciation of the use of laboratory results in patient care. Several examples of the use of the computer in quality control have been published (see Whitehead, I968; Whitehead, Becker \& Peters, 1968; Whitehead \& Carmalt, 1969). The computer is now an integral part of the clinical chemistry laboratory.

Whitehead, T. P. (1968). Bio-med. Engng 3, 467.

\section{REFERENCES}

Whitehead, T. P., Becker, J. F. \& Peters, M. (1968). Computers in the Service of Medicine Vol. I, p. I I 5. London: Shegog \& McLachlin.

Whitehead, T. P. \& Carmalt, M. H. B. (1969). Br. J. Hosp. Med. April, p. 49.

\section{The maintenance of analytical quality in the automated laboratory}

By S. C. Frazer, Department of Chemical Pathology, University of Aberdeen, Foresterhill, Aberdeen

The ways in which a laboratory's analytical work can be monitored are basically similar, whether or not the analytical processes are manual, or assisted in varying 